This PDF is a selection from a published volume from the National Bureau of Economic Research

Volume Title: Mexican Immigration to the United States

Volume Author/Editor: George J. Borjas, editor

Volume Publisher: University of Chicago Press

Volume ISBN: 0-226-06632-0; 978-0-226-06632-5

Volume URL: http://www.nber.org/books/borj06-1

Conference Date: February 11-12, 2005

Publication Date: May 2007

Title: Mexican Assimilation in the United States

Author: Edward P. Lazear

URL: http://www.nber.org/chapters/c0099 


\title{
Mexican Assimilation in the United States
}

\author{
Edward P. Lazear
}

Immigrants to the United States from Mexico become assimilated into American society much less rapidly than do other groups. A few facts from the 2000 U.S. Census make the slowness of Mexican integration apparent.

1. About 80 percent of non-Mexican immigrants are fluent in English. Among Mexicans, the number is 49 percent.

Figure 3.1 shows the differences across groups in graphic detail. The groups depicted in the graph are the largest subgroups in the 2000 Census. Mexicans clearly have the lowest average levels of fluency.

English fluency depends on the amount of time that an individual has been in the country. Figure 3.2 makes clear that Mexicans start below other groups in levels of English fluency when they arrive in the United States and never catch up. The curves never converge. Other Hispanics start above and stay above Mexicans. Non-Hispanics are significantly more fluent in English than Hispanics at all times after arrival in the United States.

2. Non-Mexican (working) immigrants have average wage income of on average \$21,000 per year. Mexican immigrants have average wage income of on average $\$ 12,000$ per year.

3. The typical non-Mexican immigrant has a high school diploma. The typical Mexican immigrant has less than an eighth grade education. Part of this may reflect differences in educational systems of the native country.

Edward P. Lazear is currently chairman of the Council of Economic Advisers. He is also the Jack Steele Parker Professor of Human Resources Management and Economics in the Graduate School of Business, and the Morris Arnold Cox Senior Fellow at the Hoover Institution, both at Stanford University.

This research was supported by CRESST and NBER. I am grateful to participants at the NBER conference on Mexican immigration and, especially, to Charlie Brown for many useful suggestions. I also thank Ben Ho for comments and assistance. 


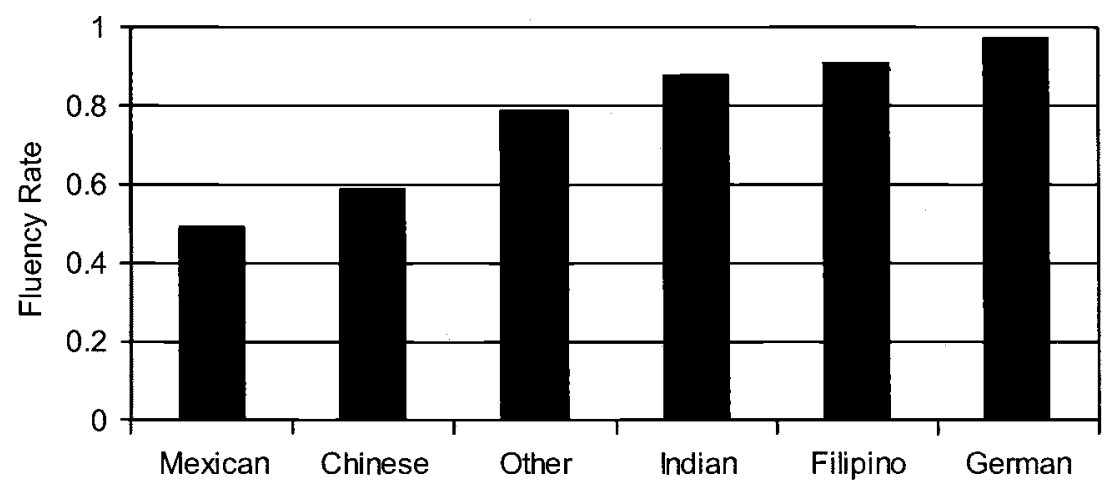

Fig. 3.1 English fluency among immigrant groups

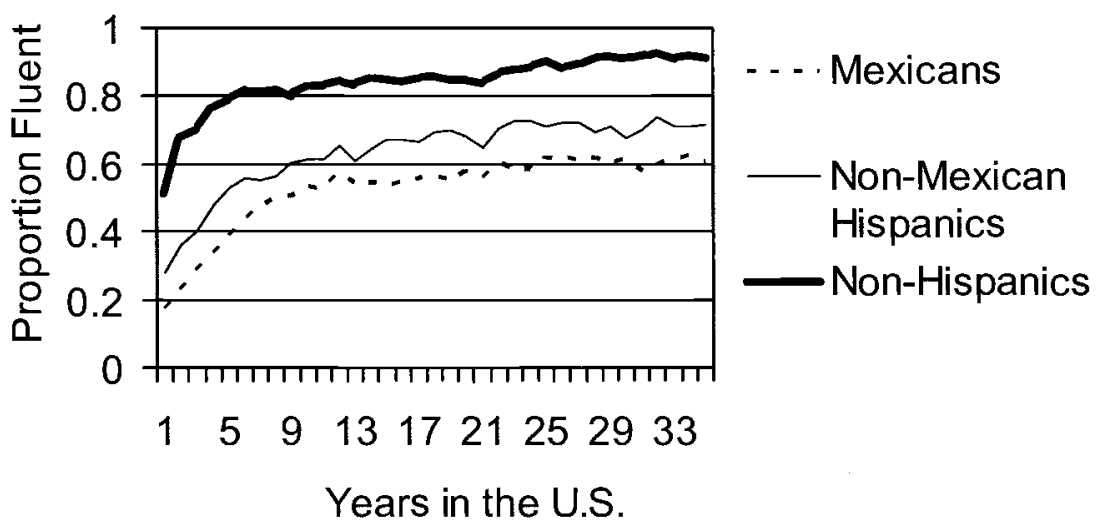

Fig. 3.2 Fluency

This is not the whole story. Even among immigrants who came to the United States before they were five years old and whose entire schooling was in the United States, those Mexican born have average education levels of 11.7 years, whereas those from other countries have average levels of education of 14.1 years. ${ }^{1}$

4. Even when compared to other Hispanics, Mexican immigrants fare badly, with 62 percent of non-Mexican Hispanics being fluent in English as compared to only 49 percent for Mexican immigrants. Mexican average incomes are about 75 percent that of other Hispanic immigrants, and Mexican immigrants have about 2.5 fewer years of schooling.

1. The sample is restricted to those who are now at least twenty-three years old so that schooling is completed for most in the sample. 
The numbers leave little doubt that Mexican immigrants do not move into mainstream American society as rapidly as do other immigrants.

Three other facts are worth noting. First, Mexican immigrants live in communities $^{2}$ where about 15 percent of the residents are also born in Mexico. Non-Mexican immigrants live in counties where fewer than 3 percent of the residents are from their specific native land. As I have argued elsewhere, the incentive to become assimilated depends in large part on the proportion of individuals in one's community who do not speak his native language or share his culture. Correcting for the difference in living patterns eliminates just about half of the fluency difference between Mexicans and other immigrants.

Second, Mexican immigrants account for a much higher proportion of the immigrant population than any other single group. Mexicans are 29 percent of immigrants in the 2000 Census. Other large groups are from the Philippines, Germany, China, and India and have shares roughly an order of magnitude smaller. Mexico is about 20 percent larger in population than the Philippines, but has about one-tenth the population of either India or China. This suggests that it is easier to obtain entry to the United States from Mexico than it is from most other countries.

Third, Mexicans come to the United States disproportionately on the basis of family connections. Other groups, most notable, Indians, come in at high levels based on job performance.

\subsection{Model}

The model used here comes from Lazear (1999). Only a sketch of the theory is provided here.

Culture facilitates trade. This is most clear in the case of language. If two agents speak the same language, they can negotiate a contract without the use of a translator. While language may be the most important manifestation of a shared culture, a common culture allows the traders to have common expectations and customs, which enhances trust.

The focus is on incentives to become assimilated, and the model presented here defines trade to include nonmarket interaction as well. ${ }^{3}$ In the simplest structure, assume that an individual randomly encounters one and only one other individual in each period. Let the expected value to one

2. Strictly speaking, the census 5 percent sample uses Public Use Microdata Area (PUMA), which is a geographic unit that is akin to county, but not the same thing in most cases.

3. The empirical literature on the economic returns to assimilation began with Chiswick (1978). More to the point of this analysis is the work by McManus, Gould, and Welch (1983), which shows that English speaking Hispanic Americans do better in the labor market than non-English speaking ones. Also, Chiswick (1991) finds that both speaking and reading fluency affect earnings, with reading fluency playing the more important role. Chiswick (1993) studies the acquisition of Hebrew language skills in Israel. As in the United States, Chiswick finds that the ability to speak the majority language increases earnings in Israel. 
party of meeting another individual with whom one can trade be normalized to be 1. For simplicity, let there be only two cultures in a country, labeled $A$ and $B$. Define $p_{a}$ as the proportion of individuals who belong to culture $A$ in equilibrium and $p_{b}$ as the proportion of individuals who belong to culture $B$ in equilibrium. The majority culture is $A$, which means that $p_{a}>$ $p_{b}$. It is possible that $p_{a}+p_{b}>1$ as one individual can belong to two cultures as, for example, in the case of bilingual persons. In order for trade to occur, an individual must encounter another individual with his own culture. If the per-trader value of a trade is 1 , then the expected gains from trade that accrues to $A \mathrm{~s}$ and $B \mathrm{~s}$ are

$$
R_{a}=p_{a}
$$

and

$$
R_{b}=p_{b} .
$$

Since $p_{a}>p_{b}, R_{a}>R_{b}$, individuals from the majority are richer than those from the minority.

Either type of individual can acquire the culture of the other group. The interest here is in minorities who acquire or choose not to acquire the language or culture of the majority. By becoming assimilated, they have the ability to trade with the majority group as well as members of their own minority. In the case of language, this can be thought of as becoming fluent in the majority language, while retaining the ability to speak the native tongue.

It is costly to acquire the new culture or to learn the new language. Define $t_{i}$ as an individual specific cost parameter that measures (inversely) the efficiency with which individual $j$ acquires the new culture with $t_{j} \sim g\left(t_{j}\right)$ having distribution $G\left(t_{j}\right)$.

A monocultural $B$ receives income $p_{b}$. If the minority member becomes bicultural, every encounter results in a trade, but $t_{j}$ is spent learning the ways of the majority. Thus, the $B$ acquires the $A$ culture if and only if

$$
\left(1-t_{j}\right)>p_{b}
$$

or if and only if

$$
t_{j}<1-p_{b} .
$$

It follows that

$$
\text { Proportion of } \begin{aligned}
B \text { s who learn } A & =\operatorname{prob}\left(t_{j}<1-p_{b}\right) \\
& =G\left(1-p_{b}\right) .
\end{aligned}
$$

Proportion $G\left(1-p_{b}\right)$ of the $B$ s are sufficiently efficient at acquiring the new culture to make it worthwhile.

Because $G\left(1-p_{b}\right)$ is decreasing in $p_{b}$, the proportion of a minority group 
that becomes assimilated into the majority culture is decreasing in the proportion of the population comprising the minority group. Also, $p_{a}>p_{b}$ guarantees that the proportion of majority members who learn the minority language is smaller than the proportion of minority members who learn the majority language.

As $p_{b}$ decreases, the minority group becomes smaller relative to the majority, which means that random contact with another is less likely to result in a trade. When $p_{b}$ is very small, minority members must be assimilated in order to survive in the society.

The key insight from this model is that high proportions of similarcultured individuals in a community retard the rate of assimilation. This effect goes part of the way to explaining the slow assimilation of Mexicans into American society. Because Mexicans live in communities with other Mexicans to a larger degree (by far) than other ethnic groups, Mexicans incentives to assimilate are reduced relative to other immigrants. But this is not the entire story. As will be shown in the following, were Mexicans in communities that resembled those of other immigrants, about half of the gap between their fluency rates and that of other immigrant groups would be closed.

\subsection{Empirical Analysis}

\subsubsection{Data}

The data come from the 2000 U.S. Census, 5 percent sample. The 5 percent sample provides far more observations than are needed, but only the 5 percent sample contains the detailed information on residential location that is necessary to perform the analysis. As a result, the 5 percent Census Public Use sample was the starting point, but from it, only one in five individuals were selected (randomly) to be included in the sample used for analysis.

The variables, their definitions, and means are given in table 3.1.

The basic argument is that slow assimilation is a characteristic of those who live in concentrated communities where a large proportion of individuals are born in their native land. The fundamental result is shown in table 3.2. Linear probability models are presented for ease of interpretation. Logit result, also provided, are virtually identical.

The basic result is clear in column (1). Those who live in concentrated areas are far less likely to be fluent in English. The coefficient on cntyprop (the proportion of individuals who are born in the respondents native country) is around -1 . This implies that going from a PUMA where everyone was born in the respondent's native land to one in which no others were born in the respondent's native land would change fluency rates from zero to 1 .

It is useful to do the same analysis for Mexicans and non-Mexican im- 
Table 3.1

Immigrant sample: Includes all in sample not born in the United States

\begin{tabular}{llrc}
\hline Variable & \multicolumn{1}{c}{ Definition } & Mean & $\begin{array}{r}\text { Standard } \\
\text { deviation }\end{array}$ \\
\hline fluent & $\begin{array}{l}\text { Dummy: 1 if respondent claims fluency in English } \\
\text { cntyprop }\end{array}$ & .71 & .45 \\
& $\begin{array}{l}\text { Proportion of other residents in PUMA who are } \\
\text { born in respondent's native country }\end{array}$ & .06 & .10 \\
yrus & Years in United States & 17.3 & 14.9 \\
cnty2 & (cntyprop) $^{2}$ & .014 & .037 \\
cntyyr & (cntyprop)(yrus) & .98 & 2.22 \\
edyrs & Highest grade of schooling completed in years & 10.8 & 5.1 \\
Mexican & Dummy: 1 if born in Mexico & .29 & .45 \\
Latin & Dummy: 1 if hispanic origin & .44 & .5 \\
cntyed & (cntyprop)(edyrs) & .55 & 1.0 \\
\hline
\end{tabular}

migrants separately. This is done in columns (3) and (4). The coefficients are smaller for Mexicans than for non-Mexicans, perhaps reflecting nonlinearities in part that will be discussed in the following.

For now, it is most instructive to use these results in order to find out how much of the difference between Mexican and non-Mexican immigrant fluency can be explained by living patterns. The mean level of cntyprop is .151 for Mexicans and .027 for non-Mexicans. The mean level of yrus is 13.8 for Mexicans and 18.8 for non-Mexicans. Using the coefficients from column (1), were Mexicans to have the same mean levels of cntyprop and yrus as other the non-Mexican immigrants, the predicted fluency rate would be 65 percent instead of the actual 49 percent, which closes about half of the gap between Mexican and non-Mexican immigrants. This is sizeable and important but does not eliminate the fluency gap between Mexican and nonMexican immigrants.

As noted, there are large differences between the coefficients in columns (3) and (4). In particular, the cntyprop coefficient is much smaller for Mexicans than for non-Mexicans. Thus, if the experiment is that of raising other immigrants' level of cntyprop to that of Mexicans, column (4) is relevant. The interpretation is that if non-Mexicans had levels of cntyprop as high (and yrus as low) as Mexicans, they would be about 15 percent less fluent than they are now, reducing their fluency rate to about 65 percent or again accounting for half of the difference. But if the experiment is that of taking Mexicans in their current communities and giving them the measured attributes of the non-Mexican immigrants, then column (3) is relevant and fluency would rise by only 7 percent or about one-fourth of the gap.

\subsubsection{Return Migration}

The preceding model is an investment model, and the return to investing in language and cultural assimilation depends on the length of time during 


\begin{tabular}{|c|c|c|c|c|c|c|c|c|}
\hline \multirow[b]{3}{*}{ Variable } & \multirow{3}{*}{$\begin{array}{c}\text { Regression } \\
\text { (1) }\end{array}$} & \multirow{3}{*}{$\begin{array}{l}\text { Logit } \\
\text { (2) }\end{array}$} & \multicolumn{2}{|c|}{ Regression } & \multirow{2}{*}{\multicolumn{4}{|c|}{ Logit }} \\
\hline & & & \multirow{2}{*}{$\begin{array}{c}\text { No } \\
\text { Mexicans } \\
\text { (3) }\end{array}$} & \multirow{2}{*}{$\begin{array}{l}\text { Mexicans } \\
\text { (4) }\end{array}$} & & & & \\
\hline & & & & & (5) & (6) & (7) & (8) \\
\hline cntyprop & $\begin{array}{c}-1.062 \\
(.007)\end{array}$ & $\begin{array}{c}-5.108 \\
(.040)\end{array}$ & $\begin{array}{l}-.988 \\
(.012)\end{array}$ & $\begin{array}{l}-.241 \\
(.014)\end{array}$ & $\begin{array}{c}-4.212 \\
(.066)\end{array}$ & $\begin{array}{c}-10.778 \\
(.114)\end{array}$ & $\begin{array}{c}-4.874 \\
(.140)\end{array}$ & $\begin{array}{c}-4.315 \\
(.146)\end{array}$ \\
\hline yrus & $\begin{array}{c}.00650 \\
(.00005)\end{array}$ & $\begin{array}{c}.04585 \\
(.00038)\end{array}$ & $\begin{array}{c}.00497 \\
(.00005)\end{array}$ & $\begin{array}{c}.00868 \\
(.00014)\end{array}$ & $\begin{array}{c}.04998 \\
(.00046)\end{array}$ & $\begin{array}{c}.08112 \\
(.00087)\end{array}$ & $\begin{array}{c}.07914 \\
(.00089)\end{array}$ & $\begin{array}{l}.06220 \\
(.00094)\end{array}$ \\
\hline cntyyr & & & & & $\begin{array}{l}-.055 \\
(.003)\end{array}$ & $\begin{array}{l}-.087 \\
(.003)\end{array}$ & $\begin{array}{l}-.076 \\
(.003)\end{array}$ & $\begin{array}{l}-.047 \\
(.003)\end{array}$ \\
\hline cnty 2 & & & & & & $\begin{array}{l}19.95 \\
(.29)\end{array}$ & $\begin{array}{l}10.06 \\
(.32)\end{array}$ & $\begin{array}{l}8.11 \\
(.34)\end{array}$ \\
\hline yrus2 & & & & & & $\begin{array}{l}-.00067 \\
(.00002)\end{array}$ & $\begin{array}{l}-.00070 \\
(.00002)\end{array}$ & $\begin{array}{l}-.00048 \\
(.00002)\end{array}$ \\
\hline Mexican & & & & & & & $\begin{array}{l}-.13 \\
(.01)\end{array}$ & $\begin{array}{l}.12 \\
(.01)\end{array}$ \\
\hline Latin & & & & & & & $\begin{array}{c}-1.09 \\
(.01)\end{array}$ & $\begin{array}{l}-.95 \\
(.01)\end{array}$ \\
\hline edyrs & & & & & & & & $\begin{array}{l}.1348 \\
(.0009)\end{array}$ \\
\hline constant & $\begin{array}{c}.662 \\
(.001)\end{array}$ & $\begin{array}{l}.552 \\
(.007)\end{array}$ & $\begin{array}{l}.729 \\
(.001)\end{array}$ & $\begin{array}{l}.408 \\
(.003)\end{array}$ & $\begin{array}{l}.492 \\
(.008)\end{array}$ & $\begin{array}{c}.478 \\
(.009)\end{array}$ & $\begin{array}{l}.859 \\
(.010)\end{array}$ & $\begin{array}{l}-.518 \\
(.014)\end{array}$ \\
\hline $\begin{array}{l}r \text {-square } \\
\text { Log }\end{array}$ & 0.1083 & & .0675 & .0426 & & & & \\
\hline likelihood & & $-168,137$ & & & -167.989 & $-164,919$ & $-158,468$ & $-147,397$ \\
\hline$N$ & 308,345 & 308,345 & 218,330 & 90,015 & 308,345 & 308,345 & 308,345 & 308,345 \\
\hline
\end{tabular}

which an individual expects to remain in the country. There are two reasons why this might be shorter for Mexicans than for non-Mexican immigrants. First, Mexico shares a border with the United States, and travel between the two is likely to be lower cost and more frequent. Second, and related, there may be a high proportion of illegal immigrants from Mexico who show up in the census data. If illegals have a shorter expected duration of stay in the United States or find it more difficult to avail themselves of the resources necessary to become assimilated and learn English, then Mexican immigrants may be adversely affected.

Evidence supports the basic ingredient behind this argument, namely that duration of time over which the language will be used affects the probability of assimilation as measured by English fluency. Including an age variable in the regression reported in table 3.2, column (1) yields a coefficient of -.00678 with a standard error of .00005 . If one thinks of each additional year of age as shorting the horizon over which English will be used by about one year, then the preceding logic that relates to return migration finds support. The effect is large. A forty-year-old immigrant is about 14 
percent less likely to be fluent in English than a twenty-year-old immigrant. ${ }^{4}$

\subsubsection{Two Mechanisms}

There are two interpretations of the results of table 3.2, both of which are consistent with the theory. One is that English is learned more rapidly by immigrants who are in integrated communities, viewing locational choice as exogenous.

The second interpretation is one of endogenous location choice. Immigrants who do not speak English may be more likely to locate in areas where there are many others who speak their language. This second view reflects the same mechanism described in this paper. Individuals who are not fluent in English move to high cntyprop areas precisely because they cannot interact with others unless they do. If it were unnecessary to be with individuals who share language to interact, the locational pattern of immigrants would be uncorrelated with English fluency. Immigrants might still cluster just because different areas settle at different times, and immigrant waves are time dependent, but there would be no reason to expect that those who did not live in highly immigrant concentrated neighborhoods would be more likely to attain English fluency.

The two interpretations are more a question of timing than of substance. Immigrants who know English had to make a decision to learn it at some point in the past. That decision was likely influenced by their desire to trade with other English speakers. Those who learn English after coming to the United States perform the same calculation but do so at a later stage. Thus, the sorting story differs from the learning story primarily on the timing at which English was learned, not on the motives for learning English. ${ }^{5}$

The coefficients in column (5) of table 3.2 allow these effects to be disentangled. If learning while in United States is the primary mechanism, then one would expect the effect of clustering to operate through the interaction with the yrus variable. Each year in the United States should be less valuable to English fluency for individuals who are in high cntyprop areas. In fact, that is what is found. Both mechanisms seem operative. Even when yrus $=0$, the effect of cntyprop on fluency is large and strong. Those who move to concentrated areas start out with a fluency deficit relative to other immigrants. It is also true, however, that those who live in concentrated areas are less likely to become fluent with each additional year in the United

4. Additionally, the sample contains young children who may not be fluent in any language. As a result, the regression run in column (1) of table 3.2 was repeated excluding children under five, eight, and ten years of age. The coefficients on both the cntyprop and yrus variables were virtually unaffected (although statistically different) by the different exclusion restrictions.

5. It is likely that those who come to the United States are not a random sample of the language-learning skill distribution. Those who find it easiest to learn English will receive higher wages when they come to the United States and are therefore more likely to emigrate from their native land. 
States than those who live in less-concentrated areas. Comparing the typical Mexican residence where cntyprop equals .151 to the typical nonMexican immigrant's residence where cntyprop equals .027 implies a reduction in the effect of years in the United States by $(.151-.027)(-.055) /$ $.05=-.136$ or by 13.6 percent of the effect of years in the United States. Both mechanisms are large and important.

Two caveats are in order. Because the data are from a single cross section and not a panel, years in the United States is not simply a duration variable but also reflects different cohorts. Those who have been in the United States longer are from an earlier cohort. To the extent that cohorts vary over time in their learning skills as argued by Borjas (1985), part of the positive effect of time in the United States reflects cohort effects. Not only would this show up as a shifter in the constant term (yrus), but it also could be related to the interaction (yrus)(cntyprop). But the effect seems to go in the wrong direction. Because the sign is negative, being in a highly concentrated area hurts learning more for early cohorts than for later cohorts. One might expect that better learners would be more immune to being in a highly concentrated area than slower learners. It is possible, however, that an argument could be made in the other direction.

Second, it is possible that those who are high-cost learners also go to highly concentrated areas. If true, then it is not only concentration per se that reduces the incentive to learn but also the fact that concentrated areas have poorer language learners.

Incidentally, there is evidence that country of origin, not merely language, is relevant, at least in terms of residential pattern. Natives of Mexico do not live in the same neighborhoods as natives of Cuba or Puerto Rico. The correlation between the proportion of a community that is Mexican and the proportion that is non-Mexican Hispanic is actually negative (-.27). If language were the only relevant factor, one would expect the correlation to be positive. ${ }^{6}$

Column (6) of table 3.2 allows nonlinear terms to enter the logit. Not surprisingly, effects are highly nonlinear. Initial years in the United States matter more than subsequent years for fluency, and going from .01 to .02 cntyprop has a larger negative effect on fluency than going from .30 to .31 cntyprop. The nonlinearity is not sufficient, however, to account for the very large differences between the linear coefficients on cntyprop in columns (2) and (3). Running linear probability regressions for Mexicans and non-Mexicans separately, while including quadratic terms, still yields very different coefficients between the two groups. Effects of cntyprop are much more damped for the Mexican group.

The logit reported in column (7) of table 3.2 shows that Hispanics are

6. See Kalnins and Chung (2004) for a study that shows that large hotels that are run by Indians do better when there are other Indians in the community, the interpretation being that individuals learn from others who share culture. Language is not the issue because virtually all are English speakers. 
less fluent in English than other groups and that Mexicans are less fluent than Hispanics. The cntyprop variable is not the whole story as already discussed previously. Both Latin and Mexican variables are important even when cntyprop is included in the logit. The difference between Mexicans and other Hispanics in fluency is more pronounced than the coefficient on the Mexican dummy in column (7) would suggest. The average level of fluency among non-Mexican Hispanics is 62 percent, whereas the average level of fluency among Mexican Hispanics is 49 percent. Recall that the logit holds cntyprop constant, but Mexicans live in more concentrated communities than other Hispanics. Non-Mexican Hispanics live in communities where the average value of cntyprop is .06 . Mexicans live in communities where the average value of cntyprop is .15 . But note that the non-Mexican Hispanic value of .06 is well above the .02 value for nonHispanics. The average level of fluency among non-Hispanic immigrants is 84 percent.

\subsubsection{Other Potential Measures}

The key variable, cntyprop, is a measure of the proportion of individuals in the census unit, PUMA, who were born in the respondent's native country. But the PUMA can be quite a large area and may not be the variable that best measures living patterns or typical encounters among individuals of various ethnic categories. For one thing, there may be a small proportion of individuals in a PUMA, but enough of them may be concentrated in a sufficient small area to provide the kind of social network that mitigates the adverse consequences lack of English skills.

There is no way using the Public Use Microdata Samples (PUMS) Census data to get more refined measures than PUMA. It might be possible to do more with the exact communities and cities using other qualitative data. The effect of using an imperfect proxy of the variable that is desired has the effect of reducing the estimated coefficient. This is a standard errors-invariables problem that biases the coefficient toward zero. (There is no obvious reason why the measurement error would be correlated with the observed variable, making it something other than white noise.) As such, the estimated effect probably understates the true effect of concentration to the extent that cntyprop measures badly the interaction or residence group in question.

\subsubsection{The Role of Income and Education}

Not surprisingly, education is closely associated with English fluency. Those who acquire more education become fluent in English, and those who plan to attain high levels of education tend to be more fluent in English. Column (8) of table 3.2 is identical to column (7), except that column (8) holds constant years of education attained. The shape of the relation of fluency to cntyprop changes slightly but remains almost the same. But it is 
clear that education is importantly related to fluency. Every additional year of education increases fluency by 2.7 percent, so going from an eighth grade education to high school graduation increases expected fluency by 11 percent.

Education is not independent of cntyprop. Those who live in high cntyprop areas get fewer years of education. Table 3.3 reports the results. In the regression in column (1), only individuals who grew up in the United States and who have likely completed their education are included. Specifically, only individuals who were older than twenty-three and who were younger than six when they came to the United States are included.

Just as in the logit on fluency, the relation of education to cntyprop is negative and convex. There are two additional points worth noting. First, even holding cntyprop constant, Mexicans and other Hispanics obtain fewer years of education than other immigrants. Second, cntyprop is a measure of current residence, not necessarily the residence where the individual was raised. So again, the exact mechanism is in question. Is living in a highly concentrated area detrimental to educational attainment, or do those who fail to get educated choose to live in concentrated areas?

The effect of concentration on fluency is more pronounced for the highly educated. Although having high levels of education implies more fluency, this is less true when the education is obtained in concentrated areas. Again, to make this claim, it is necessary that current cntyprop is a good proxy for the cntyprop relevant when the individual was growing up.

Table 3.3

Education and income results

\begin{tabular}{lcccc}
\hline & Education regression & Fluency logit & \multicolumn{2}{c}{ Log income regression } \\
\cline { 5 - 6 } Variable & $(1)$ & $(2)$ & $(3)$ & $(4)$ \\
\hline cntyprop & -4.48 & -3.51 & -1.41 & -.37 \\
& $(.99)$ & $.16)$ & $(.02)$ & $(.02)$ \\
yrus & & .0618 & .0089 & .0087 \\
& & $(.0009)$ & $(.0002)$ & $(.0002)$ \\
cnty2 & 6.22 & 8.07 & & \\
& $(2.43)$ & $.34)$ & & \\
Mexican & -1.78 & .11 & & \\
Latin & $(.10)$ & $(.01)$ & & \\
& -.29 & -.94 & & \\
edyrs & $(.07)$ & $(.01)$ & & .0715 \\
constant & & & & $(.0005)$ \\
& 14.19 & -.58 & 9.614 & 8.712 \\
$r$-square & $(.02)$ & $(.02)$ & $(.004)$ & $(.008)$ \\
Log likelihood & .0967 & & .0305 & .1078 \\
$N$ & & $-147,343$ & & \\
& 19,711 & 308,345 & 226,664 & 226,664 \\
\hline
\end{tabular}




\subsubsection{Income and Concentration}

Income is lower for individuals who live in highly concentrated areas, given education, and years in the United States. As before, the direction of causation is unclear. Those who have low incomes might choose to live in concentrated areas because rents are lower. Alternatively, those who live in concentrated areas never acquire the skills that are relevant to communities outside the concentrated ones in which they reside.

There is some suggestion of causation from cntyprop to income, however, which comes from comparing columns (3) and (4) of table 3.3. If the causation went the other way, there would be little reason to expect that holding education constant will kill off so much of the effect, as it does when it is included in the income regression. The most natural interpretation of the results is that those who live in concentrated areas obtain less education, and this has very detrimental effects on earnings. The rest of the effect in column (4) may reflect additional reductions in earnings that come from living in a concentrated area, or it may simply reflect an income effect.

The failure to identify causation in the results makes clear that it is very difficult to draw policy conclusions from the results. For example, it might be tempting to suggest that individuals might be subsidized to move out of concentrated areas. ${ }^{7}$ However, the choice of living in a concentrated area may simply be one of allocating income optimally. Even if the causation runs from concentration to income, there are costs of transition when individuals move to other areas, and those costs need to be taken into account. However, the estimates in table 3.3 can provide an upper bound to the benefits from moving from concentrated to less concentrated areas.

There may also be effects on subsequent generations. Having parents who live in concentrated areas implies that children grow up in concentrated areas. The spillover effects across generations may be quite large, suggesting additional gains to subsidizing moves outside of concentrated areas. ${ }^{8}$ (The effect must be a general equilibrium one, however. If one individual in a concentrated area is simply replaced by another similar immigrant as rent prices adjust, nothing is gained.) Unfortunately, these effects cannot be identified in the data because we only know current residence and not residence during childhood for those who are already in the labor market.

\subsection{Welfare}

Can welfare explain some of the difference between Mexican and nonMexican assimilation? Theory suggests that it might. When an individual

7. See Kling, Ludwig, and Katz (2004) on moving to opportunity.

8. See Lazear (1986) for analysis of the effects of parental education and residential location choice on income. 
can obtain government support, the value of assimilation is reduced. Welfare places a floor on the amount that an individual can earn. In the absence of government transfers, the condition for acquiring the majority culture, from equation (2), is

$$
1-t_{j}>p_{b} .
$$

A government transfer program can be thought of as guaranteeing some average level of surplus, $S$. If

$$
S>1-t_{j}>p_{b},
$$

then an individual who would have become assimilated in the absence of the government transfer will remain monocultural and will merely accept the transfer. Reducing the size of government transfers would increase the rate of assimilation in the society.

Is this what is going on, and does it affect Mexican immigrants differently from non-Mexican immigrants? The evidence suggests that it is not the explanation. Mexicans are somewhat more likely (13.1 percent versus 9.5 percent) to be on welfare than other immigrants and have almost the same amount received given that they are on welfare. The welfare explanation may have some force, but given the not enormous differences between the groups, this is unlikely to be the source of assimilation differences. Additionally, welfare is a negotiated benefit in the sense that to obtain welfare, one must apply and be approved by an agency. English speaking skills might be important in the acquisition of the benefits so the causal mechanism is confounded. (See table 3.4.)

There is some evidence, consistent with Borjas (1999), that immigrants from Mexico disproportionately go to states that have high welfare benefits. In table 3.5, column (1), a logit is run where the dependent variable is a dummy for whether the person in question is Mexican. The independent variables are the proportion of the native born population on welfare in the state in which the immigrant resides and the average level of welfare among the native born population in the state of immigrant's residence.

\begin{tabular}{lcccccc}
\hline & \multicolumn{2}{c}{ Non-Mexican } & & \multicolumn{2}{c}{ Mexican } \\
\cline { 2 - 3 } & Mean & $\begin{array}{r}\text { Standard } \\
\text { deviation }\end{array}$ & & Mean & $\begin{array}{r}\text { Standard } \\
\text { deviation }\end{array}$ \\
\hline On welfare & 9.5 & .29 & & 13.1 & .34 \\
$\begin{array}{l}\text { Dollar amount received if on welfare } \\
\text { No. with positive welfare values }\end{array}$ & 3,584 & 3,826 & & 3,595 & 3,566 \\
\hline
\end{tabular}


Table 3.5

Welfare benefits and location decisions of Mexicans

\begin{tabular}{lcc}
\hline & \multicolumn{2}{c}{$\begin{array}{c}\text { Logit dependent } \\
\text { (variable = Mexican) }\end{array}$} \\
\cline { 2 - 3 } Variable & $(1)$ & $(2)$ \\
\hline Proportion of native born in state who & 6.99 & \\
$\quad$ receive welfare (welfnatv) & $(1.26)$ & .0059 \\
Average welfare received among native & & $(.0002)$ \\
$\quad$ born in state (welfnave) & -1.03 & -1.09 \\
constant & $(.02)$ & $(.02)$ \\
& $-168,454$ & $-115,228$ \\
Log likelihood & 281,995 & 180,477 \\
$N$
\end{tabular}

\subsubsection{Immigration Policy}

Concentration of individuals in enclaves explains some of the differences in the assimilation of Mexican and non-Mexican immigrants. But it is not the entire story. Welfare may account for a small fraction of the residual but cannot be the major issue. And even if welfare differences were pronounced, it is still necessary to explain why Mexicans and non-Mexicans differ in their use of welfare.

The facts suggest that U.S. immigration policy is the culprit. Mexico is a very large country, having over 100 million people. In 2003, the United States admitted (legally) about 115,000 immigrants from Mexico. In a country as large as Mexico, it is inconceivable that there are not a sufficient number of talented potential migrants who would not assimilate more slowly than other immigrants to the United States.

The United States admits more Mexicans than any other group, accounting for 16 percent of immigrants in 2003. This ignores the illegal immigrants entirely, who are more likely to come from Mexico. Because so many come from Mexico, it is not surprising that Mexican immigrants find it easier to locate in concentrated communities.

Also revealing is the effect of admission policy. The United States admits a far greater proportion of immigrants from Mexico on a family basis (sponsored or immediate relatives) than from any other country. Put differently, the proportion of Mexicans who are admitted on employmentbased preferences is much lower than that for other immigrants. About 3 percent of Mexicans come in on employment (skills) preference, whereas 13 percent of non-Mexican immigrants come in through this channel. Some countries, like India, have a very high proportion of immigrants entering the United States on job-based visas. (See table 3.6.)

These differences might explain some of the differences between Mexicans and other groups, but probably not all. Among non-Mexicans, 13 per- 
2003 immigrants to the United States, by class of admission and country of origin

\begin{tabular}{lccrrrr}
\hline Country & $\begin{array}{c}\text { Total } \\
\text { immigrants }\end{array}$ & $\begin{array}{c}\text { Employment } \\
\text { based } \\
\text { preference }\end{array}$ & $\begin{array}{c}\text { Family } \\
\text { sponsored }\end{array}$ & $\begin{array}{c}\text { Immediate } \\
\text { relatives }\end{array}$ & Other & $\begin{array}{c}\text { Percent } \\
\text { employment } \\
\text { based }\end{array}$ \\
\hline All & 705,827 & 82,137 & 158,894 & 332,657 & 132,139 & 12 \\
Mexico & 115,864 & 3,261 & 29,664 & 78,782 & 4,157 & 3 \\
Non-Mexico & 589,963 & 78,876 & 129,230 & 253,875 & 127,982 & 13 \\
India & 50,372 & 20,560 & 15,359 & 12,693 & 1,760 & 41 \\
\hline
\end{tabular}

cent of immigrants are employment based, whereas only 3 percent of Mexicans are admitted on an employment basis. Suppose that everyone who comes in on employment basis is fluent in English. It is also true that 49 percent of the Mexican immigrants, almost all of whom come in on a nonemployment basis, are fluent in English. Converting another 10 percent of Mexican immigrants to employment based could at most raise the proportion fluent by $.10 \times .51$ or by about 5 percentage points, which would not close the gap between Mexican and non-Mexican fluency. To do that, other indirect mechanisms, involving spouses and children, would have to be important. That such factors are important is reasonable and could be examined by looking at the correlation between one immigrant's fluency and that of his family members.

The main point though seems plausible. Those who are admitted to the United States because they have desirable skills are more likely to speak English, have high levels of education, and obtain higher salaries than those who are admitted on a random or family basis. The fact that those who come in from Mexico do worse than those from other countries may reflect to a significant extent the admission policy of the United States rather than anything about country of origin. In fact, in an earlier study (Lazear 2000), it was found that the immigrants with the highest levels of education and English fluency came from North Africa. The reason is clear: it was so difficult to get into the United States from North Africa that the only individuals who succeeded in obtaining admission were those with very high skill sets.

\subsection{Conclusion}

Mexican immigrants assimilate more slowly than other immigrants as reflected in English fluency. They also have lower levels of education, lower wages, and live in more concentrated areas than other immigrants.

The source of the problem seems to be U.S. immigration policy. By admitting large numbers of Mexicans, relative to other groups on a family rather than job basis, the United States selects a group of immigrants from Mexico who are already at a disadvantage. The large numbers allow highly 